\title{
Analysis of Dystrophin Gene Deletions by Multiplex PCR in Moroccan Patients
}

\author{
Aziza Sbiti, Fatiha El Kerch, and Abdelaziz Sefiani* \\ Département de Génétique Médicale, Institut National d'Hygiène, \\ 27 avenue Ibn-Batouta, BP 769, Rabat, Morocco
}

Received 26 October 2001; revised 5 February 2002; accepted 6 February 2002

\begin{abstract}
Duchenne and Becker muscular dystrophy (DMD and BMD) are X-linked diseases resulting from a defect in the dystrophin gene located on Xp21. DMD is the most frequent neuromuscular disease in humans (1/3500 male newborn). Deletions in the dystrophin gene represent $65 \%$ of mutations in DMD/BMD patients. We have analyzed DNA from 72 Moroccan patients with $\mathrm{DMD} / \mathrm{BMD}$ using the multiplex polymerase chain reaction (PCR) to screen for exon deletions within the dystrophin gene, and to estimate the frequency of these abnormalities. We found dystrophin gene deletions in 37 cases. Therefore the frequency in Moroccan DMD/BMD patients is about 51.3\%. All deletions were clustered in the two known hot-spots regions, and in $81 \%$ of cases deletions were detected in the region from exon 43 to exon 52 . These findings are comparable to those reported in other studies. It is important to note that in our population, we can first search for deletions of DMD gene in the most frequently deleted exons determined by this study. This may facilitate the molecular diagnosis of DMD and BMD in our country.
\end{abstract}

\section{INTRODUCTION}

Duchenne and Becker muscular dystrophy (DMD and BMD) represent the most common genetic neuromuscular disease of childhood. DMD is relatively frequent, with an incidence of 1 in 3500 male live births. In a typical affected male, clinical symptoms arise around the age of 3 years with progressive muscle weakness. The patient is nonambulatory by the age of 9 or 10 years and usually dies by 20 years of age, following cardiac or respiratory complications. On the other hand, Becker muscular dystrophy (BMD) is a milder form characterized by a slower disease course, with death generally occurring in the third or fourth decade.

DMD and BMD are characterized by an X-linked pattern of inheritance, thus affecting mainly males. However, they have also been occasionally reported in females, in cases of skewed X-inactivation or X chromosome abnormalities [1].

DMD and BMD are allelic variants, produced by a defect in a large gene localized on the short arm of the $\mathrm{X}$ chromosome (Xp21). This gene was sequenced by Koenig et al [2], spans approximately 2.4 megabases and consists of at least 79 exons $[3,4]$. Its transcript is a 14 kilobase $(\mathrm{kb})$ mRNA encoding the dystrophin protein, a rod-shaped cytoskeletal protein of approximately $427 \mathrm{kda}$ molecular weight, localized to the sarcolemma inside the skeletal muscle fibres $[5,6,7]$. Western blot analysis generally shows that the dystrophin protein is absent or drastically reduced in the muscles of DMD patients, while it is present but reduced in amount and/or in size in BMD patients $[8,9]$.

In approximately $65 \%$ of $\mathrm{DMD}$ and $\mathrm{BMD}$ patients, deletions in the dystrophin gene have been identified $[2,10,11]$ without correlation between the size of the deletion and the severity of the disorder. In DMD, deletions that result in disruption of the translational reading frame prevent the production of a stable protein, while in BMD, deletions maintain the proper reading frame which results in abnormal but stable and partially functional proteins [9]. Partial duplications are responsible for 6 to $7 \%$ of DMD gene mutations [12]. Duchenne cases without deletions, representing one third of all cases [14], are probably the result of point mutations [15].

The screening for $\mathrm{DMD} / \mathrm{BMD}$ gene deletions can be carried out using Southern blotting with cDNA probes or by PCR. The latter approach allows the detection of $98 \%$ of deletions in the DMD gene [13] (64.7\% of patients).

In this paper, we report the first DNA analysis of unrelated Moroccan DMD/BMD patients by multiplex PCR. Because of its simplicity, rapidity, reduced cost, and its nonradioactive approach, this technique is very practical for the molecular diagnosis of this disorder in our country.

\section{MATERIALS AND METHODS}

\section{Patients}

All the patients were referred for DNA analysis from neurological and pediatric departments in Morocco. In some patients, dystrophin analysis by Western blot was also performed.

The diagnosis of DMD or BMD was based on clinical findings, Electromyography (EMG), the transmission of the pattern as an X-linked trait, an elevated serum creatine kinase activity, and dystrophin analysis when parental consent 


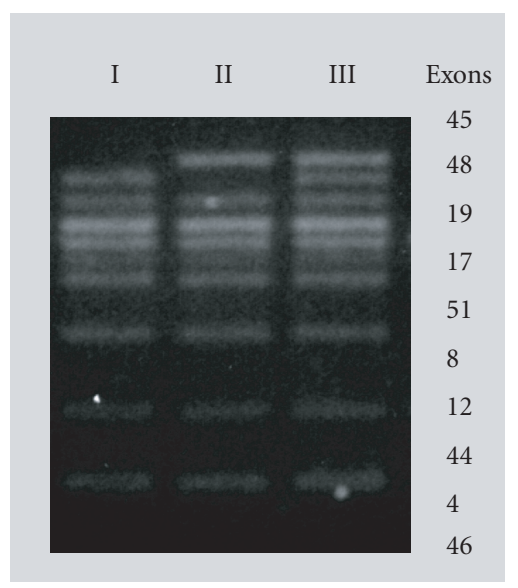

FIgURe 1. Analysis of dystrophin gene by multiplex PCR. I: patient with deletion of exon 45, II: patient with deletion of exon 48, and III: normal control. The numbers at the right indicate the amplified exons.

for a muscle biopsy was obtained. The mean age at referral was 10 years; the age range was between 4 and 32 years.

\section{Multiplex PCR}

DNA was isolated from peripheral blood leukocytes using standard phenol/chloroform procedures. Multiplex DNA amplifications of the dystrophin gene were carried out according to Chamberlain et al [16] and Beggs et al [13], using two multiplex PCR assays allowing the amplification of 9 exons each: the Chamberlain reaction using primers for exons $45,48,19,17,51,8,12,44,4$, and the Beggs reaction performed with primers for the promoter and exons $3,43,50$, $13,6,47,60$, and 52 (Figure 1). In some cases, the Chamberlain reaction modified by Beggs et al [17] allowed amplification of exon 46 plus the original set (because at the onset of this study, the primers of exon 46 were not available). The PCR products were separated on $2 \%$ nusieve $+1 \%$ agarose minigels and the bands visualized by staining with ethidium bromide.

\section{RESULTS AND DISCUSSION}

We have analysed, by multiplex PCR, 72 DNA samples from unrelated patients diagnosed with Becker or Duchenne muscular dystrophy cases based on clinical and electrophysiological findings. In 31 cases, the diagnosis was confirmed by dystrophin analysis after Western blotting and immunofluorescence (26 DMD and $5 \mathrm{BMD}$ ).

Exon deletions in the dystrophin gene were detected in 37 cases $(51.3 \%)$. All deletions were found clustered in the two deletion-prone regions identified by Koenig et al [2] (Figure 2). These findings are in agreement with other studies confirming that there are no ethnic differences in the distribution of dystrophin gene deletions [18, 19]. Among the 37 deletions detected, $81 \%$ were found in exons 43 to $52,16 \%$ in the promoter region to exon 12 and one patient

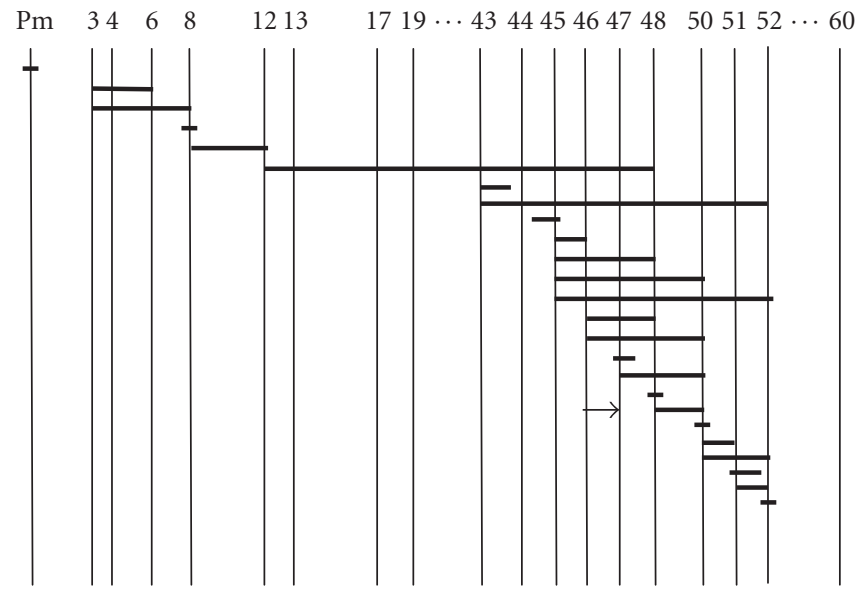

FIGURE 2. Schematic representation of different deletions in the dystrophin gene as detected in Moroccan patients (horizontal lines). The top numbers indicate the amplified exons. The arrow indicates the most frequent deletion.

mutation covered both hot spots including exon 12 region to exon 48. The most frequent deletion found in this series (detected in 5 patients) is the one spanning the region from exon 45 to exon 48.

The diagnosis of DMD or BMD was confirmed by dystrophin analysis in only 31 patients, 16 of which had dystrophin gene deletions, that is, approximately $50 \%$. In the remaining 42 cases, muscle biopsy could not be obtained either because the parents refused or because the patient was not hospitalized.

Overall, 58 patients had a confirmed dystrophinopathy, following DNA and/or dystrophin analysis, and a family history compatible with $\mathrm{X}$-linked inheritance without deletion (in 6 cases).

Among the 72 patients, 13 cases had a family history and 15 patients were inbred individuals, which represent $20 \%$ of cases. Taking into consideration this level of inbreeding, another autosomal recessive muscular dystrophy, particularly a gamma-sarcoglycanopathy, could be suspected in the fourteen remaining cases without deletion and for which no dystrophin analysis was done. With the exception of one case, all those cases were sporadic because the gammasarcoglycanopathy is also frequent in Morocco, dystrophin analysis is still important to confirm or exclude the diagnosis of DMD/BMD particularly in sporadic cases without deletion. However, detection of deletions provides accurate information for genetic counselling, and prenatal diagnosis can be proposed to female carriers. It is interesting to note that deletions in Moroccan patients are most frequent in the region from exon 43 to exon 52. For the families of DMD without deletions, linkage analysis using polymorphic markers is still the only possibility proposed to females at risk.

Duchenne muscular dystrophy patients are wheelchairbound after the first decade. In Morocco, as in many countries, this places a heavy burden on the families of the affected individuals as well as the country's health care system. The 
progress of genetic technology and the application of new approaches for DNA analysis, such as multiplex PCR, allow a rapid molecular diagnosis, which, in the absence of therapy, may currently be the only approach for prevention, through genetic counselling and prenatal diagnosis.

\section{ACKNOWLEDGMENTS}

This work was supported by l'Association Française contre les Myopathies (AFM). We greatly acknowledge Pr J. C. Kaplan, Dr D. Recan, Dr F. Leturcq, Mr J. C. Barbot, and Mr S. Llense for their technical advice.

\section{REFERENCES}

[1] Chelly J, Marlhens F, Le Marec B, et al. De novo DNA microdeletion in a girl with Turner syndrome and Duchenne muscular dystrophy. Hum Genet. 1986;74(2):193-196.

[2] Koenig M, Hoffman EP, Bertelson CJ, Monaco AP, Feener C, Kunkel LM. Complete cloning of the Duchenne muscular dystrophy (DMD) cDNA and preliminary genomic organization of the DMD gene in normal and affected individuals. Cell. 1987;50(3):509_ 517.

[3] Roberts RG, Bobrow M, Bentley DR. Point mutations in the dystrophin gene. Proc Natl Acad Sci USA. 1992;89(6):2331-2335.

[4] Roberts RG, Coffey AJ, Bobrow M, Bentley DR. Exon structure of the human dystrophin gene. Genomics. 1993;16(2):536-538.

[5] Hoffman EP, Brown RH Jr, Kunkel LM. Dystrophin: the protein product of the Duchenne muscular dystrophy locus. Cell. 1987;51(6):919-928.

[6] Koenig M, Monaco AP, Kunkel LM. The complete sequence of dystrophin predicts a rod-shaped cytoskeletal protein. Cell. 1988;53(2):219-226.

[7] Bonilla E, Samitt CE, Miranda AF, et al. Duchenne muscular dystrophy: deficiency of dystrophin at the muscle cell surface. Cell. 1988;54(4):447-452.

[8] Hoffman EP, Fischbeck KH, Brown RH, et al. Characterization of dystrophin in muscle-biopsy specimens from patients with Duchenne's or Becker's muscular dystrophy. N Engl J Med. 1988;318(21):1363-1368.

[9] Monaco AP, Bertelson CJ, Liechti-Gallati S, Moser H, Kunkel LM. An explanation for the phenotypic differences between patients bearing partial deletions of the DMD locus. Genomics. 1988;2(1):90-95.

[10] Forrest SM, Cross GS, Flint T, Speer A, Robson KJ, Davies KE. Further studies of gene deletions that cause Duchenne and Becker muscular dystrophies. Genomics. 1988;2(2):109-114.

[11] Den Dunnen JT, Grootscholten PM, Bakker E, et al. Topography of the Duchenne muscular dystrophy (DMD) gene: FIGE and cDNA analysis of 194 cases reveals 115 deletions and 13 duplications. Am J Hum Genet. 1989;45(6):835-847.
[12] Hu XY, Burghes AH, Ray PN, Thompson MW, Murphy EG, Worton RG. Partial gene duplication in Duchenne and Becker muscular dystrophies. J Med Genet. 1988;25(6):369-376.

[13] Beggs AH, Koenig M, Boyce FM, Kunkel LM. Detection of $98 \%$ of DMD/BMD gene deletions by polymerase chain reaction. Hum Genet. 1990;86(1):45-48.

[14] Prior TW. Genetic analysis of the Duchenne muscular dystrophy gene. Arch Pathol Lab Med. 1991;115(10):984-990.

[15] Roberts RG, Coffey AJ, Bobrow M, Bentley DR. Determination of the exon structure of the distal portion of the dystrophin gene by vectorette PCR. Genomics. 1992;13(4):942-950.

[16] Chamberlain JS, Gibbs RA, Ranier JE, Nguyen PN, Caskey CT. Deletion screening of the Duchenne muscular dystrophy locus via multiplex DNA amplification. Nucleic Acids Res. 1988;16(23):11141-11156.

[17] Beggs AH, Hoffman EP, Snyder JR, et al. Exploring the molecular basis for variability among patients with Becker muscular dystrophy: dystrophin gene and protein studies. Am J Hum Genet. 1991;49(1):54-67.

[18] Banerjee M, Verma IC. Are there ethnic differences in deletions in the dystrophin gene?. Am J Med Genet. 1997;68(2):152-157.

[19] Önengut S, Kavaslar GN, Battaloğlu E, et al. Deletion pattern in the dystrophin gene in Turks and a comparison with Europeans and Indians. Ann Hum Genet. 2000;64(Pt 1):33-40.

\footnotetext{
* Corresponding author.

E-mail: sefianigen@hotmail.com

Fax: +212 7 772067; Tel: +212 7771902
} 

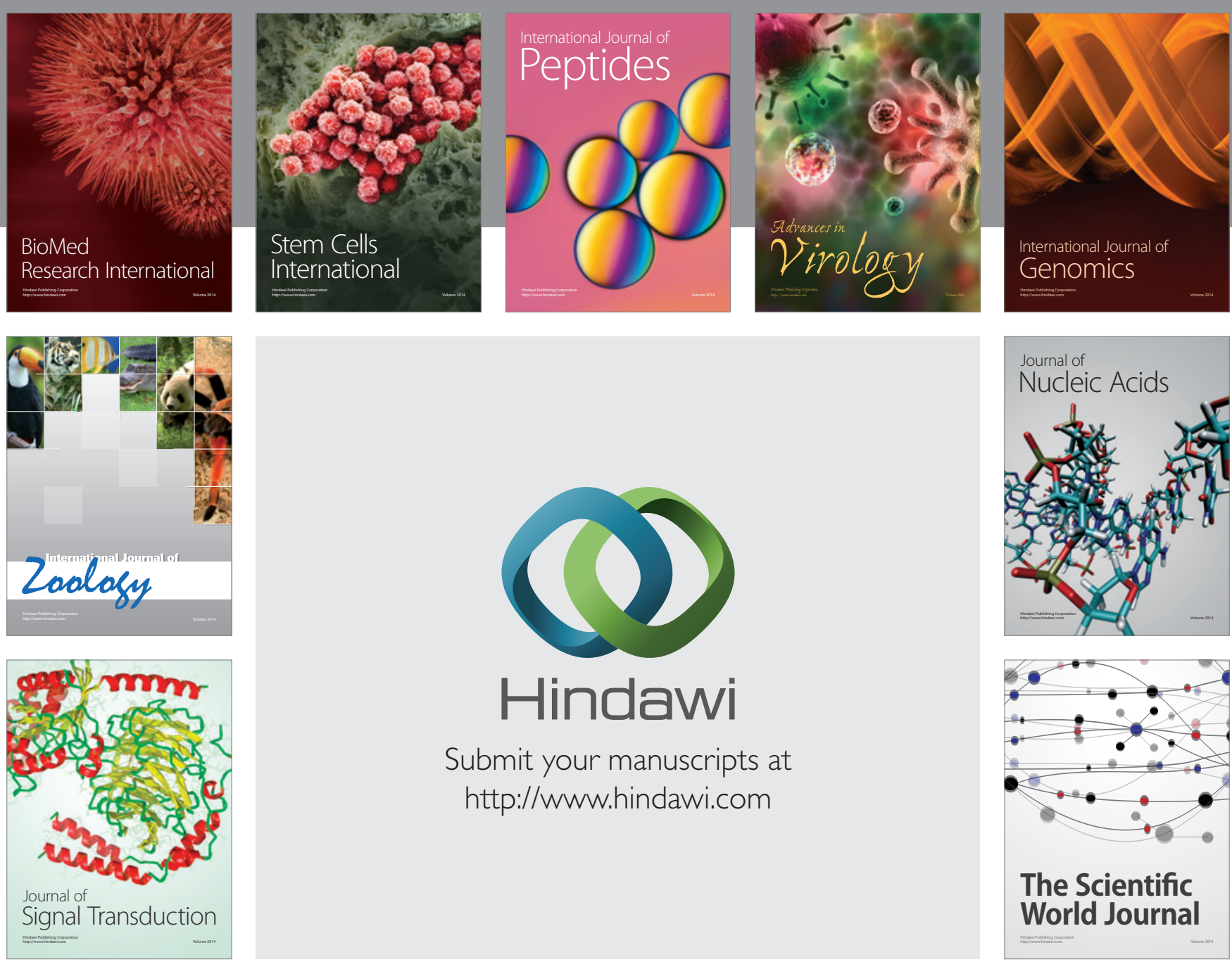

Submit your manuscripts at

http://www.hindawi.com
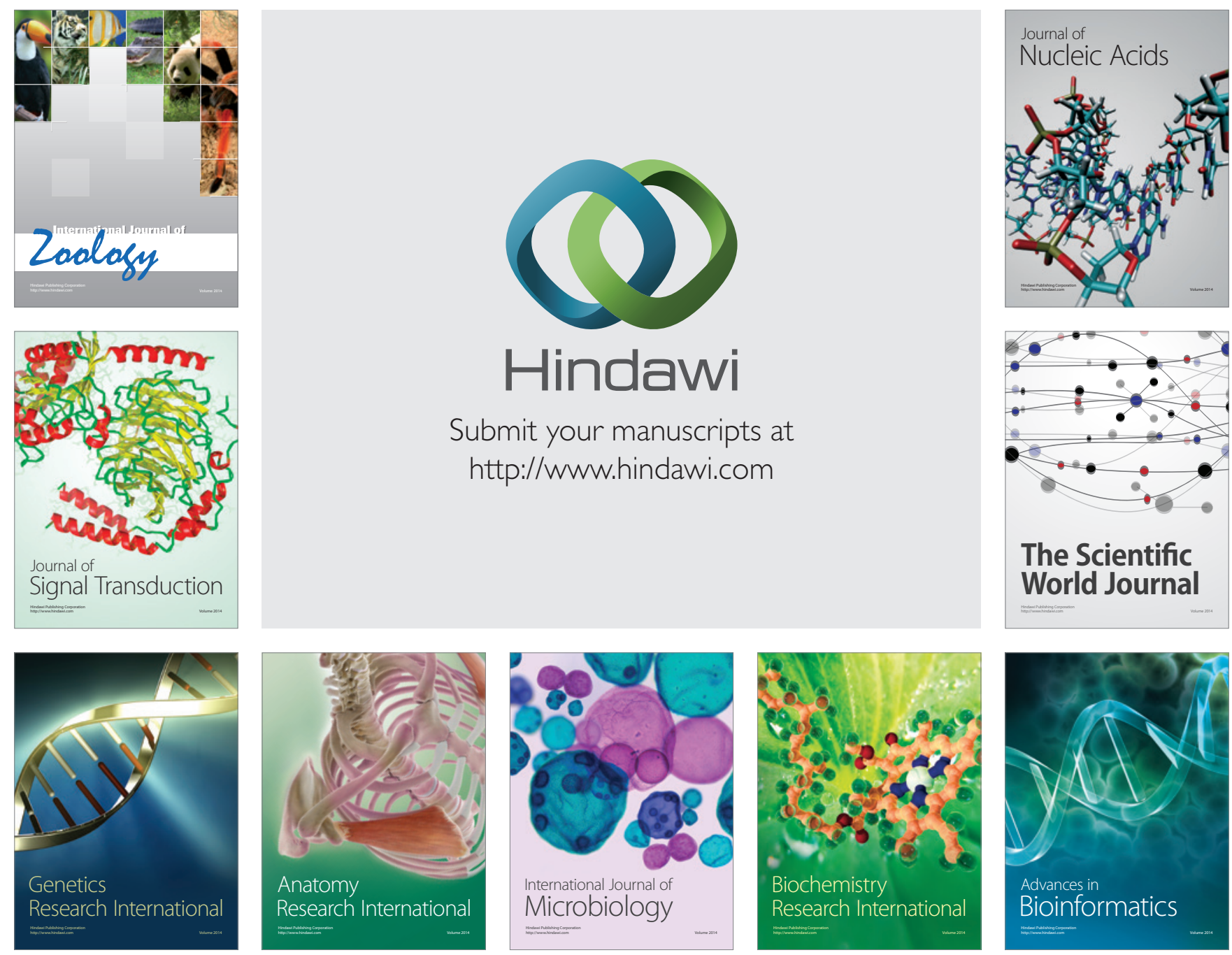

The Scientific World Journal
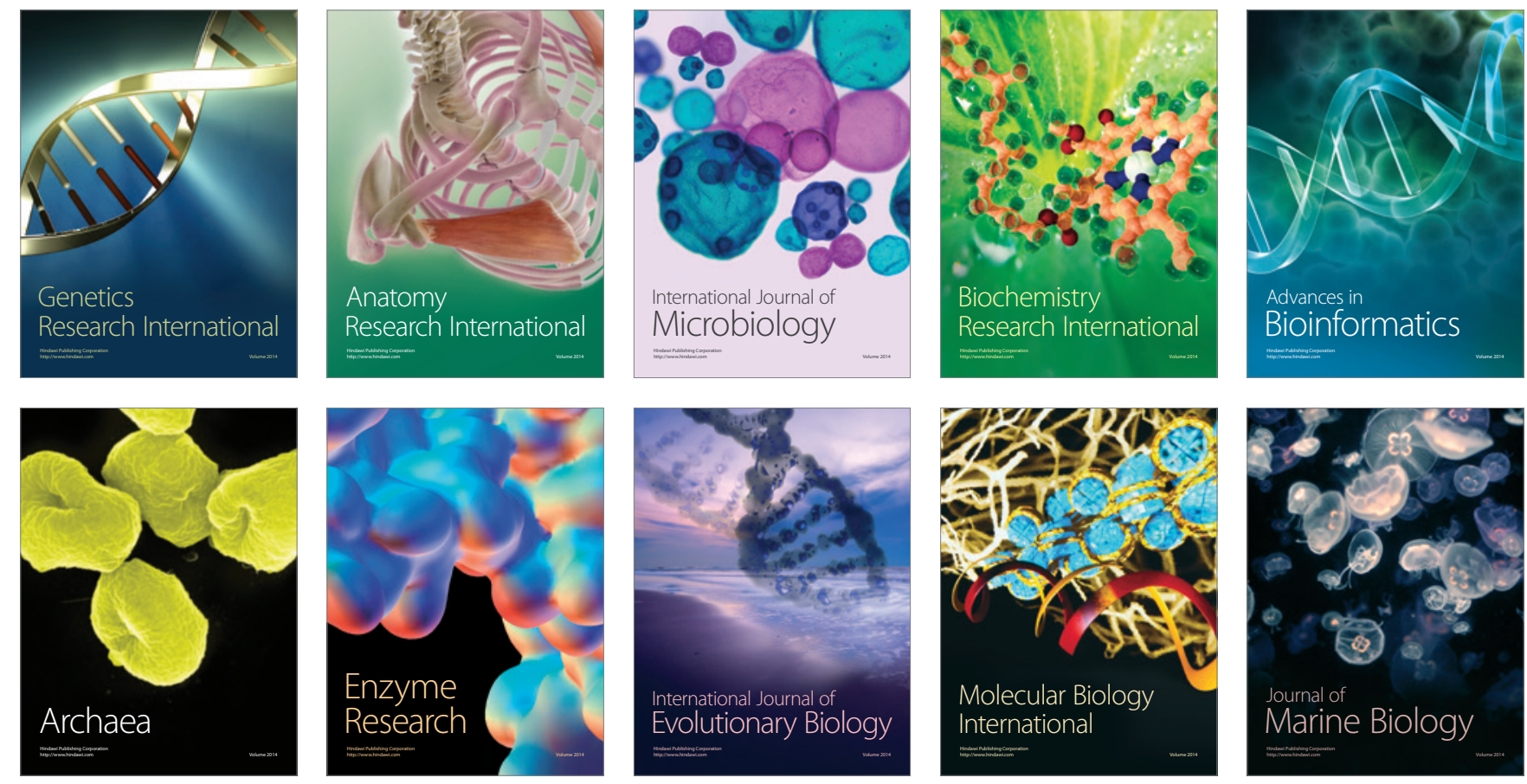